\title{
Competing for Loyalty: The Dynamics of Rallying Support
}

\author{
By Matias Iaryczower and Santiago Oliveros*
}

\begin{abstract}
We consider a class of dynamic collective action problems in which either a single principal or two competing principals vie for the support of members of a group. We focus on the dynamic problem that emerges when agents negotiate and commit their support to principals sequentially. We show that competition reduces agents' welfare with public goods, or if and only if there are positive externalities on uncommitted agents, and increases agents' welfare with public bads. We apply the model to the study of corporate takeovers, vote buying, and exclusive deals. (JEL D42, D62, D72, D82, G34, H41)
\end{abstract}

Collective action problems can make groups weak and ineffective. This issue is particularly problematic when an external principal can exploit the incentives of individual members to free ride on each other, leading the group to inefficient or inferior outcomes.

This free-riding problem appears in major applications throughout economics, including public economics (public good provision), political economy (vote buying), and industrial organization (exclusive deals). The classic reference is Grossman and Hart (1980), on corporate takeovers. Grossman and Hart show that externalities across shareholders can prevent takeovers that add value to the company. The idea is that since shareholders who do not sell can capture the increase in value brought by the raider, no shareholder will tender his shares at a price that would allow the raider to profit from the takeover.

The problem is particularly severe when the principal contracts with agents sequentially (Rasmusen, Ramseyer, and Wiley Jr. 1991; Segal and Whinston 2000; Genicot and Ray 2006), as is often the case in practice in political endorsements, vote buying, and exclusive deals. $\left.\right|^{1}$ But what if two incumbent firms were to compete for exclusive contracts, or two lobbies were to compete for committee members'

\footnotetext{
* Iaryczower: Department of Politics, Princeton University, Princeton, NJ 08544 (email: miaryc@ princeton.edu); Oliveros: Department of Economics, University of Essex, Wivenhoe Park, Essex, CO4 3SQ, UK (email: soliveb@ essex.ac.uk). This paper was accepted to the AER under the guidance of Debraj Ray, Coeditor. We thank David Ahn, Vincent Anesi, Juliana Bambaci, Antonio Cabrales, Ernesto Dal Bó, Marcelo Fernandez, Faruk Gul, Alessandro Pavan, Ariel Rubinstein, and seminar participants at UC Berkeley, U Bocconi, Bristol, Caltech, EUI, Glasgow, Harvard, Northwestern, Princeton, Queen Mary, Rice, St. Andrews, and Surrey for helpful suggestions. The authors declare that they have no relevant or material financial interests that relate to the research described in this paper.

Go to https://doi.org/10.1257/aer.20150755 to visit the article page for additional materials and author disclosure statement(s).

${ }^{1}$ Sequential contracting can arise for various reasons. A common feature of the situations in which sequential contracting is pervasive is the irreversibility of agents' actions, which is induced by contracts, reputational losses, and relation-specific investments in different contexts. In this paper, we take sequential contracting as given and explore its consequences.
} 
votes, or if the incumbent management were to fight a raider's attempt to take over the firm? Would agents benefit from competition between opposing principals in these contexts?

We address this question within a simple dynamic model in which either a single principal or two competing principals vie for the support of members of a group. Agents choose sequentially between two options and, in so doing, they interact with principals who attempt to influence their decisions. When enough agents choose one side, that side wins. ${ }^{2}$

Our main result is that competition reduces agents' welfare when the principal's policy provides value to (noncontracting) agents relative to the status quo. This is what we call a "public good" setting. In fact, when agents face two equally good alternatives, agents are always better off when facing a single principal than when facing two competing principals. In general, with public goods, agents are always better off with a monopoly of the best alternative than with competition, even if the difference in the value of the two alternatives is arbitrarily small. With "public bads," on the other hand-when the principal's policy is inferior to the status quothe results reverse, and competition is indeed beneficial to the agents.

The superiority of monopoly to competition depends crucially on the nature of the free-riding effect. With positive externalities on uncommitted agents, agents benefit from not trading with the principal. In this context, free-riding opportunities give agents bargaining power vis-à-vis the principal. Competition harms agents because it reduces the value of free-riding and, thus, diminishes their bargaining power. ${ }^{3}$ As we show in the paper, in fact, this result is true for not only the case of two principals but whenever multiple principals compete for the support of the group.

In the main part of the paper, we present a minimal model in which followers' payoffs at terminal nodes are unaffected by whether they supported the winner, the loser, or remained uncommitted. This model allows us to isolate the key aspects of the problem, but it is not well suited for applications where this distinction is natural. In Section IVB, we remove this assumption and apply the insights of the model to corporate takeovers, vote buying, and exclusive deals. The expanded model also clarifies that the key consideration for our result is whether completion of the project implies a positive or negative externality on "uncommitted" followers.

All proofs are in online Appendix A.

\section{Related Literature}

Our paper contributes primarily to the literature on "contracting with externalities." These papers explore problems in which a single principal contracts with a group of agents in the presence of externalities among agents. The most closely related papers are Rasmusen, Ramseyer, and Wiley Jr. (1991); Segal and Whinston (2000); and Genicot and Ray (2006), which study sequential contracting..$^{4}$ These

\footnotetext{
${ }^{2}$ Prat and Rustichini (2003) also study contracting with multiple principals and multiple agents, but they do so in a static setting with private values and no externalities, and focus on efficiency concerns.

${ }^{3}$ The importance of positive and negative externalities as well as increasing or decreasing externalities among agents in contracting models was first highlighted in a static setting by Segal (1999). The focus of this paper is how the types of externalities among agents affect efficiency. See also Segal (2003).

${ }^{4}$ See also Galasso (2008); Möller (2007); and Rasmusen and Ramseyer (1994).
} 
papers show that when agents impose negative externalities on each other by contracting with the principal, sequential contracting exacerbates the free-rider problem among agents..$^{5}$ The literature on contracting with externalities is closely related to our monopolistic model (Section III), where the externality is due to the fact that agents make a collective decision.

The key innovation of our paper is to extend the model of sequential contracting with externalities to a competitive setup and, primarily, to compare the welfare of agents under monopoly and competition. ${ }^{6}$ In fact, as we foreshadowed above, the result that monopoly is preferred to competition with public goods depends crucially on the nature of the free-riding effect introduced by Grossman and Hart (1980) and is linked to the direction of externalities on nontraders emphasized by Segal (1999).

Our paper also contributes to the literature on "vote buying" and interest group influence developed in political economy. In these papers, two lobbyists compete to offer transfers to members of a committee to obtain their support in favor of or against a bill (see, for example, Myerson 1993, Groseclose and Snyder 1996). Our paper is closest to Dekel, Jackson, and Wolinsky (2008, 2009). The fundamental innovation here is to introduce sequential vote buying with two principals and strategic agents. Our paper is also related to the models of innovation races pioneered by Harris and Vickers $(1985,1987)$. However, there are important differences. Most directly, although we focus on agents' welfare, these agents are absent in the models of races, which focus on the game among principals. As a result, the free-riding problem at the core of our analysis is absent in this literature, as is the interaction of principals with strategic, forward-looking agents. 7

Finally, our conclusion relates to Olson's (2000) governance argument that a stationary monopolistic bandit may be better than competition. Both arguments are fundamentally about externalities. Olson's argument is that the monopolistic leader internalizes to a larger extent the effect of her actions on the total surplus. In our model, instead, agents prefer monopoly to competition when competition reduces their bargaining power vis-à-vis the leaders by reducing free-riding opportunities.

\section{The Model}

Two leaders, $\mathrm{A}$ and $\mathrm{B}$, compete to gather the support of a majority of agents (followers) in a group of size $n$. The first leader to obtain the commitment of $q \equiv(n+1) / 2$ members wins and implements her preferred alternative. There are an infinite number of periods, $t=1,2, \ldots$ In each period $t$ before a leader wins, any one of the $k(t)$ uncommitted followers at time $t$ meets leader $\ell=A, B$ with probability $\pi_{\ell} / k(t)>0$, where $\pi_{A}+\pi_{B}=1$. Say that at the time of the meeting, $\ell$ needs $m_{\ell}$ additional followers to win, and let $\vec{m} \equiv\left(m_{A}, m_{B}\right)$. In a meeting with an

\footnotetext{
${ }^{5}$ Segal and Whinston (2000), Segal (2003), and Dal Bó (2007) show that the principal can exploit agents in a static setting if she can make discriminatory offers.

${ }^{6}$ The literature on noncooperative coalitional bargaining games with externalities considers general bargaining problems with multiple agents (Bloch 1996; Ray and Vohra 1999, 2001; Gomes 2005; Gomes and Jehiel 2005). These papers aim to establish efficiency, existence, and uniqueness properties in this class of games.

${ }^{7}$ More indirectly, our paper connects with the literature on competition in public goods (see Bergstrom, Blume, and Varian 1986 and Ghosh, Karaivanov, and Oak 2007), in which individuals simultaneously choose contributions to multiple public goods. In these papers, consumers do not interact with the principals influencing their decisions.
} 
uncommitted follower $i$, leader $\ell$ makes an offer $p_{\ell}(\vec{m}) \in \mathcal{R}$ to secure $i$ 's support. ${ }^{8}$ Follower $i$ can accept or reject $\ell$ 's offer; if he accepts, $i$ commits his support for $\ell$ and receives $p_{\ell}(\vec{m})$, and if he rejects, $i$ remains uncommitted.

Leader $\ell$ gets a payoff of $\bar{v}_{\ell}>0$ if and when she wins and $\underline{v}_{\ell}$ if and when her opponent $j \neq \ell$ wins, where $\bar{v}_{\ell}>\underline{v}_{\ell}$. In any period before a leader wins, both leaders get a payoff of zero (a normalization). Followers get a payoff $w_{\ell}$ if and when leader $\ell$ wins and a payoff of zero in each period $t$ before a leader wins. We initially assume that both leaders provide value to the agents, i.e., $w_{\ell}>0$ for $\ell=A, B$. We refer to this case as the public good case. We then consider the public bad case, in which $w_{\ell}<0$ for $\ell=A, B$. Leaders and followers have discount factor $\delta \in(0,1)$.

The solution concept is Markov perfect equilibrium (MPE). We let $W(\vec{m})$ denote the continuation value of an uncommitted follower in state $\vec{m} \equiv\left(m_{A}, m_{B}\right), W_{\text {out }}(\vec{m})$ denote the continuation value of a committed follower in state $\vec{m}$, and $V_{\ell}(\vec{m})$ denote the continuation value of leader $\ell$ in state $\vec{m}$. We also define $\vec{m}^{A} \equiv\left(m_{A}-1, m_{B}\right)$ and $\vec{m}^{B} \equiv\left(m_{A}, m_{B}-1\right)$.

As a benchmark, we also consider the case in which there is only one alternative to the status quo. The model is the same as before, with $\pi_{\ell}=0$ for some $\ell=A, B$. We denote the payoffs that the leader and a follower obtain when the leader wins by $v$ and $w$, with $w>0$ in the public good case. Leader and followers obtain a payoff of zero in any period before the leader wins. The state is the number $m$ of additional followers the leader needs to win. The offer in state $m$ is $p(m)$; the values of uncommitted and committed followers are $w(m)$ and $w_{\text {out }}(m)$, respectively; and the leader's value is $v(m)$.

\section{Monopolistic Leadership}

We begin by characterizing MPE of the public good model with a single alternative. Here, we proceed informally. Consider first the critical follower facing the leader when $m=1$. Note that since $v, w>0$, the leader and follower would jointly benefit from moving forward, securing the leader's victory. Thus, there is a transfer that makes moving forward mutually beneficial and, in any equilibrium, there must be a transaction when $m=1$.

In fact, this must be true in equilibrium in all states $m \leq q$ : the leader makes an offer in every meeting until she collects a majority of followers, and the uncommitted followers who meet the leader accept these offers. We refer to this as a full trading equilibrium (FTE). To see why this is an equilibrium, suppose there are $m>1$ followers remaining. Since in the proposed equilibrium there is trade whenever the leader needs to secure the support of $t<m$ additional followers, in $m$ it is also jointly beneficial for the leader and follower to move forward, just as in $m=1$. As a result, here again there is a transfer that makes an agreement mutually beneficial.

Now, consider any MPE, and suppose that there is trade whenever the leader needs to secure the support of $t<m$ additional followers. If in state $m$ the leader does not make an offer with positive probability or the follower does not accept

\footnotetext{
${ }^{8}$ This assumption is prevalent in the literature on contracting with externalities (see, however, Galasso 2008). Giving followers some bargaining power does not change our results.
} 
the offer with positive probability, the leader and follower would obtain a lower combined payoff in state $m$ than in the equilibrium with trade. Hence, the gain from moving forward would be higher than in the FTE and thus positive. It follows that the leader will make an offer, which the follower will accept. We then have the following result.

PROPOSITION 1: The unique MPE of the game $\Gamma^{s}(q)$ is a full trading equilibrium. In this equilibrium, the payoff of a follower is given by

$$
w(q)=\left(\prod_{m=1}^{q} r(m)\right) \delta^{q} w \quad \text { for } \quad r(m) \equiv \frac{n+2 m-3}{n+2 m-1-2 \delta} .
$$

Proposition 1 implies that in equilibrium the leader cannot extract all surplus from the followers. The logic is similar to that behind the underprovision of a public good, where agents can free ride on other agents. Note that since followers benefit from implementing the alternative to the status quo, the leader actually charges them to move on. By rejecting the offer, a follower can rely on others to pay the bill. This possibility generates an outside option that gives followers bargaining power over the leader.9 Since the cost of deferring implementation of the proposal decreases with $\delta$, the value of the outside option is increasing in $\delta$, as is the followers' equilibrium payoff. In fact, as $\delta$ approaches $1, r(m) \rightarrow 1$ and $w(q) \rightarrow w$. Moreover, since the probability that the follower is able to free ride until completion increases the closer the leader is to winning, the value of the outside option is decreasing in $m$. Thus, conditional on trading at some point, a follower is better off if approached later in the process, i.e., $w(m) / \delta w(m-1)=r(m)<1$ for all $m$.

\section{Competition and Main Result}

Consider next the competitive game $\Gamma^{c}(q, q)$ with two alternatives to the status quo, $A$ and $B$, and initial position $\vec{m}=(q, q)$. Recall that we defined $\vec{m}^{A} \equiv\left(m_{A}-1, m_{B}\right)$ and $\vec{m}^{B} \equiv\left(m_{A}, m_{B}-1\right)$. Follower $i$ accepts an offer $p_{\ell}(\vec{m})$ from $\ell$ only if $p_{\ell}(\vec{m})+\delta W_{\text {out }}\left(\vec{m}^{\ell}\right) \geq \delta W(\vec{m})$, and he accepts with probability 1 if this inequality is strict. Thus, in equilibrium, if $\ell$ makes an offer, she offers

$$
p_{\ell}^{*}(\vec{m}) \equiv-\delta\left[W_{\text {out }}\left(\vec{m}^{\ell}\right)-W(\vec{m})\right] .
$$

The offer by $\ell$ has to compensate $i$ for what he would obtain if he were to refuse to commit his support for $\ell$, taking him —along with the entire group_-back to the position $\vec{m}$. Leader $\ell$ is willing to make this offer if $p_{\ell}^{*}(\vec{m}) \leq \delta\left[V_{\ell}\left(\vec{m}^{\ell}\right)-V_{\ell}(\vec{m})\right]$, or, substituting $p_{\ell}^{*}(\vec{m})$ from $(1)$, if the surplus for $i$ and $\ell$ of taking $\ell$ one step closer to the goal is nonnegative, i.e.,

$$
S_{\ell}(\vec{m}) \equiv\left[V_{\ell}\left(\vec{m}^{\ell}\right)-V_{\ell}(\vec{m})\right]+\left[W_{\text {out }}\left(\vec{m}^{\ell}\right)-W(\vec{m})\right] \geq 0
$$

\footnotetext{
${ }^{9}$ As we show in Section IVB, when we allow payoffs to depend on whether each follower backed a winning or losing candidate or remained uncommitted, the public good model is consistent with both positive and negative transfers. In fact, in all applications we consider, the transfer from the principal to the agents is positive, even with public goods. The direction of the cash transfer is not essential to our result.
} 
In the natural extension of the full trading equilibrium in the monopolistic case to the competitive game, leaders make relevant offers in all states $\vec{m}$ such that $m_{A}, m_{B} \leq q$. Unlike its counterpart in the monopoly game, this strategy profile is not always an equilibrium in this context. With this in mind, in the next proposition, we establish two results. First, we prove that the competitive game has an MPE equilibrium. Second, we provide a sufficient condition for the existence of an FTE in the competitive game, and we characterize the value of an uncommitted follower in an FTE. ${ }^{10,11}$ In stating this result, we adopt the convention that for any $f(\cdot), \sum_{k=a}^{b} f(k)=0$ if $b<a$.

\section{PROPOSITION 2:}

(i) The competitive game $\Gamma^{c}(q, q)$ has an MPE.

(ii) All else equal, if the leaders' payoff for winning is sufficiently high, the game has an FTE, with the value of an uncommitted follower in state $\vec{m}$ given by

$$
\begin{gathered}
W(\vec{m})=\sum_{j=A, B}\left(\delta \pi_{j}\right)^{m_{j}}\left[\sum_{l=0}^{m_{-j}-2}\left(\prod_{k=0}^{m_{j}-1+l} r\left(m_{-j}+m_{j}-k-\frac{n+1}{2}\right)\right)\right. \\
\left.\times\left(\begin{array}{c}
m_{j}-1+l \\
m_{j}-1
\end{array}\right)\left(\delta \pi_{-j}\right)^{l}\right] w_{j} .
\end{gathered}
$$

As in the single principal case, the value of the outside option is increasing in $\delta$, and so are followers' equilibrium payoffs. However, with competition, the equilibrium payoff of followers does not necessarily increase as any principal gets closer to winning. The key point to note is that, with competition, there are multiple paths to terminal states, which generally differ in the probability that an agent will be able to free ride along the path. In particular, lopsided wins for the principal who is advantaged in expectation allow a large number of followers to remain uncommitted along the path and thus maximize free-riding opportunities. On the contrary, the probability of free riding is minimized in tight races. As we will show below, in fact, followers' payoffs are not necessarily increasing along the diagonal (see Example 1) or as we move forward in any given direction. However, there is always a leader $\ell \in\{A, B\}$ such that moving in $\ell$ 's direction increases followers' equilibrium payoffs (first part of the proof of Theorem 1 ).

We are now ready to compare followers' equilibrium payoffs under monopoly and competition. We begin by considering the FTE of the competitive game with three followers.

\footnotetext{
${ }^{10}$ Note that this equilibrium is inefficient, as the worst alternative wins with positive probability. This result is in line with the literature on noncooperative coalitional bargaining games with externalities, which has shown that inefficiency is the norm in this class of games (Bloch 1996; Ray and Vohra 1999, 2001; Gomes 2005; Gomes and Jehiel 2005).

${ }^{11}$ Note that $W(\vec{m}) \rightarrow w_{A}(m)$ (as characterized in Proposition 1) as $\pi_{B} \rightarrow 0$.
} 
Example 1: Suppose $n=3$. Consider first the state $\vec{m}=(1,1)$, reached after one follower has committed to each leader. From (1), leader $\ell=A, B$ offers the follower $p_{\ell}(1,1)=\delta\left[W(1,1)-w_{\ell}\right]$, which the follower accepts. Thus,

$$
W(1,1)=\pi_{A}\left(p_{A}(1,1)+\delta w_{A}\right)+\pi_{B}\left(p_{B}(1,1)+\delta w_{B}\right)=\delta W(1,1),
$$

so that $W(1,1)=0$. Because only one follower remains uncommitted, there are no free-riding possibilities, and all surplus is extracted by the leaders. Consider next the state $\vec{m}=(1,2)$. As before, a follower meeting the leader gets a payoff $\delta W(1,2)$, and, thus,

$$
W(1,2)=\frac{1}{2} \delta W(1,2)+\frac{1}{2}\left(\pi_{A} \delta w_{A}+\pi_{B} \delta W(1,1)\right) .
$$

Thus, $W(1,2)=\left(\delta \pi_{A} /(2-\delta)\right) w_{A}>0=W(1,1)$. Similarly, $W(2,1)$ $=\left(\delta \pi_{B} /(2-\delta)\right) w_{B}$, and, then,

$$
W(2,2)=\left(\frac{2 \delta^{2}}{3-\delta} \frac{1}{2-\delta}\right)\left(\left(\pi_{A}\right)^{2} w_{A}+\left(\pi_{B}\right)^{2} w_{B}\right)
$$

Now, from the single leader case, we have

$$
w(2)=\left(\frac{2 \delta^{2}}{3-\delta} \frac{1}{2-\delta}\right) w
$$

Note that the expression in parentheses is equal to the corresponding expression in (4). Thus, if $w=w_{A} \geq w_{B}$, followers prefer a monopoly of $A$ to competition between $A$ and $B$ for any discount factor $\delta<1$. Furthermore, when $\Delta w=w_{A}-w_{B}$ is small, followers also prefer a monopoly of $B$ to competition if $\pi_{A} \approx 1 / 2$.

The fact that in this example there are only three agents is not important for this result. Indeed, a comparison of followers' values in Propositions 1 and 2 shows that the example generalizes to an FTE with $n$ agents. The example illustrates two important lessons. First, since a monopoly can improve followers' welfare relative to competition even for $\delta \rightarrow 1$, the reason that followers are better off under single leadership is not solely explained by delay. Second, because sometimes a monopoly of the worst leader dominates competition, the reason behind the followers' welfare ordering cannot be solely due to the risk of ending up collectively selecting the worst choice available.

The key to understanding the result is in how the followers' bargaining power changes across the two games. Followers prefer monopoly to competition because competition reduces their free-riding ability, which directly lowers their bargaining power vis-à-vis the leaders. This is captured in equation (3), which shows that the source of value is the probability of all paths leading to successful free riding until completion.

To see this intuitively, consider the problem of the "critical" follower in monopoly (the $q$ th member to meet the leader). If the critical follower refuses an offer by the leader, he will be able to free ride on others with probability $(n-q) /(n-q+1)$. This relatively high free-riding ability gives the critical follower considerable 
bargaining power against the leader and protects him from being fully expropriated. Now consider the problem of a critical follower under competition (a follower who could give one of the leaders a win). The number of uncommitted followers in this situation is at most as large as in monopoly. In fact, if the battle between the leaders is even until the end, the critical follower could meet the leader in state $\vec{m}=(1,1)$. But here there are no free-riding possibilities.

This situation is extreme, but the logic generalizes to other states in which the number of uncommitted followers is lower than in the single alternative case. To see this, consider the competitive and monopolistic games with $n=5$ and $w_{A}=w_{B}=w$. Using Proposition 1 and equation (3), $w(3)>W(3,3)$ boils down to $1>\sum_{j=A, B}\left(\pi_{j}\right)^{3}\left[1+\frac{3}{2-\delta}\left(\delta \pi_{-j}\right)\right]$. Letting $\gamma(\vec{m})$ denote the probability of reaching the node $\vec{m}$ from the initial node $(q, q)$ in a competitive equilibrium, we can write this as

$$
(1-\delta)[\gamma(2,1)+\gamma(1,2)+\gamma(1,1)]+\frac{1}{2} \delta \gamma(1,1)>0
$$

Expression (5) shows that the difference in value across games comes from those nodes in which the number of uncommitted followers cannot be reached in monopoly. 12

In the discussion so far, we have assumed an FTE in the competitive game. For some parameters, though, equilibrium will require that one of the leaders does not make an offer in some states, or only makes an offer with positive probability. Moreover, in contrast to the monopoly game, we cannot guarantee that the equilibrium of the competitive game will be unique. Theorem 1 - our main result — shows that the result holds for any number of agents $n$ and any MPE.

THEOREM 1: Let $W(q, q)$ denote the payoff of an uncommitted follower in an $M P E$ of the game with two alternatives $A$ and $B$ such that $w_{A} \geq w_{B}>0$. Then, (i) $W(q, q)<w_{A}(q)$. Moreover, (ii) there exists $\varepsilon>0$ such that if $w_{A}-w_{B}<\varepsilon$, $W(q, q)<w_{B}(q)$.

The proof is by induction and consists of four steps:

(i) In any state $\vec{m}$, there is an alternative $j \in\{A, B\}$ such that followers are better off after moving one step in the direction of $j$, i.e., $W(\vec{m})<\max _{j \in\{A, B\}} \times\left\{W\left(\vec{m}^{j}\right)\right\}$.

(ii) When a principal $j$ is one step away from winning, followers would be strictly better off by removing one of the alternatives from consideration, e.g., $W\left(m_{A}, 1\right)<\max \left\{w_{A}\left(m_{A}\right), w_{B}(1)\right\}$. (Connects the competitive and monopolistic games.)

\footnotetext{
${ }^{12}$ Both delay and free riding vanish as $\delta \rightarrow 1$ because patience eliminates the source of power that free riding gives to the followers. However, these are two distinct effects. In fact, delay is not necessary for the result. Note that as $\delta \rightarrow 1$ all terms vanish except $\vec{m}=(1,1)$, in which the remaining follower has no opportunity to free ride.
} 
(iii) Combining steps (i) and (ii), we show that when principal $j$ is two steps away from winning, followers would be strictly better off removing one of the alternatives from consideration, e.g., $W\left(m_{A}, 2\right)<\max \left\{w_{A}\left(m_{A}\right), w_{B}(2)\right\}$ for all $m_{A} \geq 2$.

(iv) Induction step for $\vec{m} \geq(3,3)$ : if $W\left(\vec{m}^{B}\right) \leq \max \left\{w_{A}\left(m_{A}\right), w_{B}\left(m_{B}-1\right)\right\}$ and $W\left(\vec{m}^{A}\right) \leq \max \left\{w_{A}\left(m_{A}-1\right), w_{B}\left(m_{B}\right)\right\}$, then $W(\vec{m}) \leq \max \left\{w_{A}\left(m_{A}\right)\right.$, $\left.w_{B}\left(m_{B}\right)\right\}$.

Theorem 1 states that a monopoly of the better alternative is better for followers than competition at the beginning of the game, from a position of symmetry. ${ }^{13}$ The sketch of the proof, however, makes clear that the comparison holds in the entire state space. It follows that the presence of an initial advantage would not alter our results.

COROLLARY 1: Let $W\left(q_{A}, q_{B}\right)$ denote a follower's payoff in an MPE of the competitive game with initial position $\left(q_{A}, q_{B}\right), q_{A}<q_{B}$. Then, $W\left(q_{A}, q_{B}\right)<$ $\max \left\{w_{A}\left(q_{A}\right), w_{B}\left(q_{B}\right)\right\}$.

Corollary 1 allows us to extend the benchmark model to arbitrary nonunanimous $q$-rules. Say $B$ needs to obtain the support of a supermajority $q_{B}>(n+1) / 2$ of members to implement a reform leading to a value of $w_{B}>0$ for the followers, whereas $A$ can block the reform by getting the support of $q_{A}=n-q_{B}$ members, leading to $w_{A}=0$. This model is formally equivalent to introducing initial advantages, with the exception that $w_{A}=0$. Thus, Corollary 1 applies to this case as stated. ${ }^{14}$

Part (i) of Theorem 1 and Corollary 1 focus on the comparison of competition with a monopoly of the best alternative. Part (ii) of the theorem, on the other hand, shows that followers can prefer a monopoly of the worst alternative to competition, provided that the two alternatives are sufficiently close to one another. This outcome is striking. In our next result, we pursue this outcome further and provide conditions under which this result can be extended to any $w_{A}, w_{B}>0$.

THEOREM 2: Let $W(q, q)$ denote the payoff of an uncommitted follower in an FTE of the competitive game with $w_{A}, w_{B}>0$. Then, there exists $\bar{n}$ such that if $q=(n+1) / 2>\bar{n}, W(q, q)<\min \left\{w_{A}(q), w_{B}(q)\right\}$.

Theorem 2 builds on the same core intuition behind our main result. Note that in monopoly, the probability that the critical uncommitted follower will be able to free ride after refusing an offer from the leader is $(n-1) /(n+1)$, which goes to 1

\footnotetext{
${ }^{13}$ Our statement concerns only followers' welfare. In the special case of $\delta \rightarrow 1, w_{A}=w_{B}=w$, and an FTE in competition, the overall surplus is in fact unchanged and, thus, the aggregate welfare of the leaders is larger in competition. In general, competition can increase or decrease total welfare.

${ }^{14}$ Because unanimity eliminates free-riding opportunities, monopoly under unanimity is worse for followers than competition under simple majority. We can then show that for any submajority rule $Q$ in competition, there exists a rule $\hat{q}(Q) \geq Q$ in monopoly such that the value of an uncommitted follower under competition with rule $Q$ is at most (at least) the value of an uncommitted follower under monopoly with rule $\hat{q}(Q)-1$ (with rule $\hat{q}(Q)$ ). We thank an anonymous referee for pointing this out.
} 
as $n \rightarrow \infty$. On the other hand, the competitive game can turn out to be very close, even in a large group. In this case, a critical follower in the competitive game can find himself to be one of only a few uncommitted followers and, as a result, have few free-riding opportunities and therefore less bargaining power. This effect trickles down to the beginning of the game and, then, even a monopoly of the worst alternative is preferred to competition.

We have repeatedly emphasized the crucial role of free riding for our result. A natural question, then, is whether Theorem 1 can be generalized to $K>2$ principals. Intuition suggests that if anything, the free-riding argument should be even stronger in this case.

The case with many principals is more complex due to the higher dimensionality of the problem. A key object in the two-leader problem is the set of states in which one trade exhausts free-riding opportunities. With two leaders, this happens at $\vec{m}=(1,2)$ with a trade with $B$ and at $\vec{m}=(2,1)$ with a trade with $A$. With more than two leaders, there are multiple states in which a single transaction exhausts free-riding opportunities. What allows us to deal with this higher dimensionality is that the states in which a transaction exhausts free-riding opportunities are conceptually equivalent to each other and that the states in which no transaction exhausts free-riding opportunities are conceptually equivalent to each other, so that the key at any state is to separate transactions that lead the process to one or the other set of states. From this point on, we can then prove the result with a generalization of the arguments in the proof of Theorem 1.

THEOREM 3: Let $W^{K}(\vec{q})$ denote the payoff of an uncommitted follower in an MPE of the game with $K>2$ alternatives $\ell=1,2, \ldots, K$ such that $w_{1}>$ $w_{2}>\cdots>w_{K}>0$ with initial position $\vec{q}=\left(q_{1}, q_{2}, \ldots, q_{K}\right)$. Then, $(i) W^{K}(\vec{q})$ $<\max _{\ell}\left\{w_{\ell}\left(q_{\ell}\right)\right\}$. Moreover, (ii) if $q_{\ell}=q$ for all $\ell \in K$, there exists $\varepsilon>0$ such that for any $\ell=1, \ldots, K$, if $w_{1}-w_{\ell}<\varepsilon, W^{K}(\vec{q})<w_{\ell}(q)$.

\section{A. Public Bads}

Up to this point, we assumed that the alternatives under consideration are public goods, in the sense that followers prefer the outcome associated with a victory of $A$ or $B$ to the status quo. The logic of the proof of Theorem 1, however, suggests that the analysis above applies to public bads (i.e., $w_{A}, w_{B}<0$ ) almost unchanged, reverting the result. Intuitively, since with public bads followers can only cut their losses if they are part of the coalition that supports the leader, a critical agent that refuses the offer with a single alternative will have a much lower chance of being brought back to the negotiating table than a critical follower in a competitive environment. As a result, the critical follower in a competitive environment can demand a higher transfer in exchange of his support.

In order to apply this result, we first need to establish existence of an FTE in monopoly with public bads. The next proposition shows that the FTE is still the unique MPE as long as the leader's win value is sufficiently high and, moreover, that any MPE with transactions is an FTE. 
PROPOSITION 3: Let $w<0$. Any MPE is either an FTE or involves no transactions. Moreover, there exists $\bar{v}>0$ such that if $v \geq \bar{v}$, the FTE is the unique MPE of the game.

Proposition 3 says that if the leader's win value is sufficiently large, a leader representing a policy that is arbitrarily bad for followers can win with the support of a majority of the group. This is, of course, terrible news for those agents who are not compensated. In fact, $w(q)$ goes to the upper bound of 0 as $\delta \rightarrow 0$ and to the lower bound of $w<0$ as $\delta \rightarrow 1$. The reason is that the leader pits uncommitted followers against each other, as in Genicot and Ray (2006). Upon meeting, both the leader and follower know that if the follower rejects the leader's offer, the next follower will accept it. Thus, the follower can only delay the implementation of the public bad for one period if he forgoes any compensation. To prevent this delay, the leader can offer to compensate the follower for this differential only (and not for the full cost that implementation will bring to the follower).

With the previous result, we can establish formally our main conclusion. ${ }^{15}$

PROPOSITION 4: Let $w_{A}, w_{B}<0$. Let $W(q, q)$ denote the initial value of an uncommitted follower in an MPE of the competitive game, and let $w_{k}(q)$ denote the initial value of an uncommitted follower in an MPE with trade of the game in which $k=A, B$ is the only principal. Then, $W(q, q) \geq \min \left\{w_{A}(q), w_{B}(q)\right\}$.

\section{B. Applications}

In this section, we extend the insights of the model to applications. In order to do so, we consider an extended version of the model where we distinguish between the insider payoff $z_{\ell}$ obtained by an individual who gave her support to $\ell$ when $\ell$ wins, the outsider payoff $w_{\ell}$ obtained by an uncommitted follower when $\ell$ wins, and - in the competitive model - the rival payoff $y_{\ell}$ obtained by an individual who gave her support to $j \neq \ell$ when $\ell$ wins. We consider three examples: corporate takeovers, vote buying with audience costs, and exclusive deals. In corporate takeovers, completion is a public good for uncommitted followers. In our vote-buying example, completion can be desirable for uncommitted followers but is bad for committed followers due to audience costs. In exclusive deals, completion is a public bad for both committed and uncommitted followers. We begin by describing the three examples. We then proceed to the analysis of the extended model and its implications for each of these cases.

Example 2 (Corporate Takeovers): Grossman and Hart (1980)-henceforth, $\mathrm{GH}$ - analyze a problem in which a company (the raider) acquires shares of a target company to control its board of directors. It is assumed that the raider can improve the value of the company. To capture this feature, we assume that under the raider's control, the value of a share is $w>0$, and we normalize the value of a share under the incumbent management to zero. We distinguish the payoff that a shareholder

\footnotetext{
${ }^{15}$ Part (ii) of Theorem 1 goes as well, as do Corollary 1 and Theorem 2.
} 
obtains when the raider wins if the shareholder does not sell to the raider $(w>0)$ from the payoff he obtains if he does sell to the raider $(z=0) .{ }^{16}$ We then consider introducing competition from a second principal (e.g., the incumbent management).

Example 3 (Vote Buying): Here, we consider a model of sequential vote buying. ${ }^{17}$ We think of this model as capturing a process of coalition building that occurs in office deals prior to the moment the proposal is on the floor for a vote, at which point allegiances are typically already decided. ${ }^{18}$ To fix ideas, then, consider a national legislature which is about to vote on a fiscal restraint bill proposed by the executive. We assume that legislators privately favor the bill $(w>0)$. Voters, however, oppose it, so that supporting the bill is costly for legislators, i.e., $z<0<w$. We then introduce a second option. The executive's proposal (say, $A$ ) aims to reduce the deficit by increasing taxes, whereas an alternative proposal favored by a powerful lobby $(B)$ seeks to reduce public expenditures. We assume that legislators prefer increasing taxes, so that $w_{A}>w_{B}>0$.

Example 4 (Exclusive Deals): We consider a problem in which two firms compete for a product market with increasing returns to scale signing exclusive contracts with buyers. Our motivating example is the HD optical disc format war between Blu-ray and HD DVD. This problem relates to the analysis in Rasmusen, Ramseyer, and Wiley Jr. (1991) and Segal and Whinston (2000), with two key differences. First, we allow both the incumbent and the challenger to sign exclusive contracts. We also assume that both firms are initially competing in the market. Thus, ours is a model where firms take actions to induce exit as opposed to deterring entry. Suppose, without loss of generality, that $\mathrm{A}$ is the better technology. Then, $y_{A} \geq y_{B}$ and $z_{A}=w_{A} \geq z_{B}=w_{B}$. As is standard in the literature, we assume that buyers' prices would increase if one of the incumbents exits, so that $w_{j}=z_{j}<0$ for $j=A, B$.

Consider first an FTE in monopoly. ${ }^{19}$ Because in equilibrium the follower is indifferent between accepting or rejecting the offer, the payoff of a follower meeting the leader in state $m$ is $\delta \hat{w}(m)$. As a result, the recursive representation of the value of uncommitted followers is unchanged from the benchmark game (see equation (8) in the proof of Proposition 1), and, thus, so is its solution, $\hat{w}(m)=\left(\prod_{k=1}^{m} r(m)\right) \delta^{m} w$. The value of a committed follower, on the other hand, is now given by $\hat{w}_{\text {out }}(m)=\delta^{m} z \leq 0$ in Examples 2, 3, and 4. Substituting

$$
\hat{p}(m)=\delta^{m+1}\left(\left[\prod_{k=1}^{m} r(k)\right] w-z\right)>0,
$$

\footnotetext{
${ }^{16} \mathrm{As}$ in GH and Segal (2003), we assume that shareholders are homogeneous. Unlike GH, we suppose that shareholders are fully aware of the effect of their action on the outcome of the raid attempt. Holmström and Nalebuff (1992) show that when shareholdings are divisible, the free-riding problem does not prevent the takeover process in the $\mathrm{GH}$ model.

${ }^{17}$ See Rasmusen and Ramseyer (1994), Genicot and Ray (2006) with a single principal, and Dekel, Jackson, and Wolinsky $(2008,2009)$ with two principals and nonstrategic agents.

${ }^{18}$ This is in the spirit of Iaryczower and Oliveros (2016), who study intermediaries in legislative bargaining.

${ }^{19}$ In Proposition A.9 (online Appendix A), we show that whenever $z \leq 0<w$, the FTE is the only robust MPE with trade, and it is the unique MPE for high $v$. The result for Example 4 follows directly from Proposition 3.
} 
so that transfers are positive in all three cases even as $w>0$. In fact, $\hat{p}(m) \rightarrow w-z$ for all $m$ as $\delta \rightarrow 1$. In the takeover context, this means that, as frictions vanish, the raider has to fully compensate shareholders, as in GH. For any $\delta<1$, however, $\hat{p}(m)<w$, and the raider can appropriate some of the surplus it generates. ${ }^{20}$ In addition, from $(6)$ we have $\hat{p}(m-1)-\hat{p}(m)>0$. Thus, the price curve is decreasing in $m$, so that agents who transact first obtain a lower compensation.

How would competition affect agents' welfare in these contexts? The fact is that our main result is not affected by the direction of transfers. The reason is that, in equilibrium, followers are indifferent between accepting or rejecting the offer, and the payoff of a follower meeting the leader in state $\vec{m}$ is $\delta \hat{W}(\vec{m})$ independently of whether he accepts or rejects the leader's offer. Because of this, as in monopoly, the recursive representation of the followers' value is unchanged from the benchmark model (see equation (16) in the proof of Proposition 2) and, thus, so is its solution, i.e., $\hat{W}(\vec{m})=W(\vec{m})$. This implies that the followers' value only depends on the outsider payoffs $w_{\ell}$, with all the new elements going into the revised cash transfer $\hat{p}_{\ell}(\vec{m})$.

It follows that the relevant factor determining the effect of competition is whether uncommitted followers would benefit or lose from the completion of the project(s) relative to the status quo, i.e., competition is bad for followers when the externality on uncommitted followers is positive and is beneficial when this externality is negative. In the case of takeovers, in particular, this result says that shareholders would not benefit from competition between raiders. This is also the case in Example 3, as stated, when legislators would gain if the bill passes without their support. If, however, we assume that both voters and legislators equally dislike the project, so that $z=w<0$, competition between lobbyists would increase legislators' welfare. In our exclusive deals Example 4, there are negative externalities on uncommitted agents, $w_{j}<0$, and competition increases followers' welfare.

\section{Discussion}

In this paper, we considered a class of dynamic collective action problems in which either a single principal or multiple competing principals vie for the support of members of a group. We have shown that when principals' success benefits uncommitted agents, competition among principals harms agents because it reduces their bargaining power. Before concluding, we discuss two key assumptions in the model: the (un)observability of trades and (in)direct competition. ${ }^{21}$

Unobservable Trades. - A core assumption in our model is that past deals are observable, so that the state, $m$ or $\vec{m}$, is common knowledge. This assumption captures what we believe is an important dynamic aspect of these problems. This

\footnotetext{
${ }^{20}$ This result is similar to that of Harrington and Prokop (1993), who consider a dynamic version of GH in which the raider can reapproach the shareholders who have not sold (at the posted prices). One should not conclude from this that the leader would always prefer sequential to static contracting or vice versa. (See online Appendix B.5.)

${ }^{21}$ In online Appendix B.3, we discuss an extension of the model in which followers can choose to reject offers permanently, leaving the pool of uncommitted followers, and in online Appendix B.4, we revisit our assumption that leaders offer cash transfers in exchange for a commitment of support, allowing instead promises of transfers contingent on winning (a partnership offer instead of a buyout).
} 
assumption, however, is not neutral for followers' equilibrium payoffs. Common knowledge about the state affects outcomes in both monopoly and competition because the state affects the value of free-riding opportunities and, thus, agents' bargaining power. Whether unobservability would upend or reinforce the results in the benchmark model depends on whether it increases agents' bargaining power in competition significantly more than it does in monopoly or if the reverse is true. To explore this question, in online Appendix B.1, we analyze the monopoly and competitive games under nonobservability for $n=3$, following Noe and Wang (2004). We show that even in this case, monopoly is preferred to competition because the unobservability of trades does not change the underlying fact that the expected value of free-riding opportunities (now also over states) is larger under monopoly than under competition.

Direct Competition.- - In our model, we assume a sequential contracting setup, in which leaders and followers make deals in bilateral meetings. We believe that this is a natural setup for the applications we have in mind, where individual deals are more common than organized markets. A consequence of this assumption is that competition is indirect in the sense that it affects trades only through its effect on followers' outside options. ${ }^{22}$ In online Appendix B.2, we introduce the possibility of direct competition, i.e., with probability $\pi_{A B}>0$, both leaders make simultaneous offers to the followers. Direct competition improves the standing of competition vis-à-vis monopoly because followers can extract additional rents from the winning leader. This new effect now competes with the free-riding effect, which favors monopoly, and it can overturn the free-riding effect for some configurations of parameters. However, because additional rents are heavily captured by agents at the later stages in the game, followers see a reduced advantage from direct competition in early stages. Because of this, our results are quite robust to the presence of direct competition, even when $\pi_{A B}$ is large and frictions are small (for $\delta$ close to 1$)$.

Much work remains. A promising direction for future research is a systematic treatment of competitive sequential contracting with heterogeneity among followers. In our model, we have assumed agents are ex ante homogeneous. This seems to be a reasonable first step. First, because agents are ex ante homogeneous, any differential treatment an agent obtains in equilibrium is only due to the state in which he bargains with the leader(s). This allows us to cleanly isolate the core mechanism in the model. Second, having a homogeneous pool of agents leads to an unambiguous comparison of agents' welfare under monopoly and competition. Third, this assumption simplifies the analysis considerably. The difficulty is that heterogeneity increases the size of the state space substantially, because the state space must now also keep track of the identity and characteristics of each one of the uncommitted followers. This feature becomes relevant, as leaders may want to exclude some agents from negotiations in order to extract more surplus from other followers, introducing strategic distributional considerations. Potential equilibrium strategies, then, quickly become very complicated as $n$ increases, as trades depend

\footnotetext{
${ }^{22}$ This is how competition among proposers enters in the vast majority of collective bargaining models, including all models in the tradition of Baron and Ferejohn (1989) and Chatterjee et al. (1993).
} 
on a very large state space. With this caveat in mind, we believe that a full analysis of competitive sequential contracting with heterogeneity among followers will open interesting questions. We leave this endeavor for future research.

\section{REFERENCES}

- Baron, David P., and John A. Ferejohn. 1989. "Bargaining in Legislatures.” American Political Science Review 83 (4): 1181-206.

Bergstrom, Theodore, Lawrence Blume, and Hal Varian. 1986. "On the Private Provision of Public Goods." Journal of Public Economics 29 (1): 25-49.

- Bloch, Francis. 1996. "Sequential Formation of Coalitions in Games with Externalities and Fixed Payoff Division." Games and Economic Behavior 14 (1): 90-123.

-Chatterjee, Kalyan, Bhaskar Dutta, Debraj Ray, and Kunal Sengupta. 1993. "A Noncooperative Theory of Coalitional Bargaining." Review of Economic Studies 60 (2): 463-77.

-Dal Bó, Ernesto. 2007. "Bribing Voters." American Journal of Political Science 51 (4): 789-803.

Dekel, Eddie, Matthew Jackson, and Asher Wolinsky. 2008. "Vote Buying: General Elections." Journal of Political Economy 116 (2): 351-80.

Dekel, Eddie, Matthew O. Jackson, and Asher Wolinsky. 2009. "Vote Buying: Legislatures and Lobbying." Quarterly Journal of Political Science 4 (2): 103-28.

-Galasso, Alberto. 2008. "Coordination and Bargaining Power in Contracting with Externalities." Journal of Economic Theory 143 (1): 558-70.

-Genicot, Garance, and Debraj Ray. 2006. "Contracts and Externalities: How Things Fall Apart." Journal of Economic Theory 131 (1): 71-100.

Ghosh, Suman, Alexander Karaivanov, and Mandar Oak. 2007. "A Case for Bundling Public Goods Contributions." Journal of Public Economic Theory 9 (3): 425-49.

-Gomes, Armando. 2005. "Multilateral Contracting with Externalities." Econometrica 73 (4): 1329-50.

-Gomes, Armando, and Philippe Jehiel. 2005. "Dynamic Processes of Social and Economic Interactions: On the Persistence of Inefficiencies." Journal of Political Economy 113 (3): 626-67.

-Groseclose, Tim, and James M. Snyder, Jr. 1996. "Buying Supermajorities.” American Political Science Review 90 (2): 303-15.

Grossman, Sanford J., and Oliver D. Hart. 1980. "Takeover Bids, the Free-Rider Problem, and the Theory of the Corporation." Bell Journal of Economics 11 (1): 42-64.

-Harrington, Joseph E., Jr., and Jacek Prokop. 1993. "The Dynamics of the Free-Rider Problem in Takeovers." Review of Financial Studies 6 (4): 851-82.

-Harris, Christopher, and John Vickers. 1985. "Perfect Equilibrium in a Model of a Race." Review of Economic Studies 52 (2): 193-209.

-Harris, Christopher, and John Vickers. 1987. "Racing with Uncertainty." Review of Economic Studies 54 (1): 1-21.

- Holmström, Bengt, and Barry Nalebuff. 1992. "To the Raider Goes the Surplus? A Reexamination of the Free-Rider Problem." Journal of Economics and Management Strategy 1 (1): 37-62.

- Iaryczower, Matias, and Santiago Oliveros. 2016. "Power Brokers: Middlemen in Legislative Bargaining." Journal of Economic Theory 162: 209-36.

-Möller, Marc. 2007. "The Timing of Contracting with Externalities." Journal of Economic Theory 133 (1): 484-503.

-Myerson, Roger B. 1993. "Incentives to Cultivate Favored Minorities under Alternative Electoral Systems." American Political Science Review 87 (4): 856-69.

Noe, Thomas H., and Jun Wang. 2004. "Fooling All of the People Some of the Time: A Theory of Endogenous Sequencing in Confidential Negotiations." Review of Economic Studies 71 (3): $855-81$.

Olson, Mancur. 2000. Power and Prosperity: Outgrowing Communist and Capitalist Dictatorships. New York: Basic Books.

-Prat, Andrea, and Aldo Rustichini. 2003. "Games Played through Agents." Econometrica 71 (4): 9891026.

- Rasmusen, Eric, and J. Mark Ramseyer. 1994. "Cheap Bribes and the Corruption Ban: A Coordination Game among Rational Legislators." Public Choice 78 (3-4): 305-27.

Rasmusen, Eric B., J. Mark Ramseyer, and John S. Wiley, Jr. 1991. "Naked Exclusion." American Economic Review 81 (5): 1137-45.

-Ray, Debraj, and Rajiv Vohra. 1999. "A Theory of Endogenous Coalition Structures." Games and Economic Behavior 26 (2): 286-336. 
- Ray, Debraj, and Rajiv Vohra. 2001. "Coalitional Power and Public Goods.” Journal of Political Economy 109 (6): 1355-84.

-Segal, Ilya. 1999. “Contracting with Externalities.” Quarterly Journal of Economics 114 (2): 337-88.

-Segal, Ilya. 2003. "Coordination and Discrimination in Contracting with Externalities: Divide and Conquer?" Journal of Economic Theory 113 (2): 147-81.

-Segal, Ilya R., and Michael D. Whinston. 2000. "Naked Exclusion: Comment." American Economic Review 90 (1): 296-309. 